\title{
Everybody's publishing but me! How a writing group can help actualize your publishing dreams
}

\section{$\mathbf{O}$} $\mathrm{n}$ any given day, one can go to the Chronicle of Higher Education and see a new article on the trials and tribulations of publishing and seeking tenure in academia. Anxiety inducing titles such as "Measuring Up" and "The Stress of Academic Publishing" reaffirm the notion that one must publish, or perish. While this type of pressure pushes some to success, for others, it makes it harder to write. However, you don't have to travel this writing and publishing road alone. Inspired by the book Every Other Thursday: Stories and Strategies from Successful Women Scientists by Ellen Daniell, a small group of women academics and professionals in Logan, Utah found their support team through the creation of a writing group in Spring 2009. ${ }^{1}$

While the group's membership has changed over the years due to job changes and moves to new cities, each member draws upon and supports the writing group in different ways.

What follows is the collaborative efforts of three of the group members. In sharing guiding principles for creating a group, individual reflections, and a list of suggested resources, it is our hope that others feeling lonely or isolated will be inspired to find their own support team and embrace their identity as writers.

\section{What is a writing group, and how can you create your own?}

Writing groups can take many forms and range in style from informal gatherings to regularly scheduled commitments with timekeepers and agendas. Regardless of structure, the end goal is to use the dynamic and communal setting of the group to move writing projects forward. In some iterations, individuals might bring writing samples and get immediate feedback. Or, as is the case with our writing group, members report on our goals, discuss questions they might have in moving forward, and then set specific tasks to be completed by the next meeting. However, we haven't always followed this same routine.

As our group approaches its ten year anniversary, we've learned a lot about what makes a group work, and why our group might struggle at times. Based on this experience and the strategies outlined in Daniell's book, we identified four guiding principles that together help keep a writing group strong: 1) build your group dynamic, 2) make scheduling happen, 3) devise a method for setting goals, and 4) establish conversation ground rules.

One of the hardest aspects of starting a writing group is figuring out who should actually be in the group. We found that a

Dory Rosenberg is reference and instruction librarian at Utah State University, email: dory.rosenberg@ usu.edu, Karin M. Kettenring is associate professor of Wetland Ecology at Utah State University, email: karin.kettenring@usu.edu, and Anne R. Diekema is instruction and outreach librarian at Southern Utah University, email: annediekema@suu.edu

๑ 2019 Dory Rosenberg, Karin M. Kettenring, and Anne R. Diekema 
group of three-to-six individuals is our ideal number and makes it easier for everyone to share and listen. In terms of group composition, our members have primarily been in varying disciplines. While this was initially happenstance, we found that working with individuals outside one's own field of study helps eliminate worries of professional competition, and, in general, expands the skill set of the group. Finally, find people you genuinely enjoy being around and people who can contribute to a supportive and non-judgmental group dynamic.

The second guiding principle that keeps our group afloat is that we collectively designate a recurring face-to-face meeting time at the beginning of each semester. We typically meet once every two weeks in the evening time, and at the end of each meeting we decide where the next meeting will be held. We take turns hosting at our respective houses, and a few times every semester we meet at a local restaurant, where we celebrate semester milestones and special events. While drinks and food are good additions to any writing group meeting, remember to set the schedule early and to make the location convenient for all.

So you finally have your group of writers together, now what? In her book, Daniell talks about language her group uses to describe their goal-setting process. While you don't need to create your own lingo, it is important to devise a method for tracking goals and a strategy for how members will report on their progress. Over the years, we've used various methods of tracking goals, including a detailed Google document and a more informal group text thread.

Regardless of how you track your goals, the goals need to be specific, and they should outline realistic writing tasks that you can complete before the next meeting. And when that next meeting comes around, how will group members report their progress so everyone has a chance to share? In the beginning, each member of our group stated an amount of time they needed (ranging from five-to-ten minutes), and then one member was a designated timekeeper. We've now moved to a more relaxed format, where we first catch up on each other's lives over dinner and then end the session with brief individual reports on our previous and upcoming goals.

Our final guiding principle is the principle to rule them all. To make sure the group stays healthy and happy, it's important to establish ground rules for conversation at the get-go. For example, will all conversations related to group time remain strictly confidential? Or is it okay for group members to share ideas and experiences discussed with spouses, partners, or co-workers outside the group? Since writing groups are essentially trust networks, each member needs to be clear about communication expectations within the group and how to talk about the group with others.

It's easy enough to list guiding principles and say "hop to it," but do writing groups actually work? Is all the time and effort needed to keep a group sustainable worth it in the long run? In hopes of answering both of these questions with a resounding "yes," the following are reflections from group members that include a description of the life events each member was experiencing when they joined the group, three lessons learned from participating in the writing group, and a description of where each member is now in their writing and publishing journey.

\section{Reflections}

\section{Moving from Perfection to Good Enough- Dory}

When I joined the writing group in 2014, I was a new faculty librarian at Utah State University. I was concerned with how to document the impact of my work, and I wondered if my ideas and writing would be good enough for publication. The following distills three major lessons from my writing group experience that help me manage work anxiety and the publication process:

- Go beyond your library circle. From working with nonlibrary colleagues, I 
learned new writing strategies and an understanding of other disciplines that continue to help me become a better subject librarian.

- Find your "good enough." Research and writing can take as much time as you give them. The writing group helped me come to terms with the idea of "good enough," but at the same time pushes me when I become too lax in my goals.

- Challenge your habits. I have struggled with perfecting my ideal task management system. My revelation was that I need different systems throughout the semester and that trying new strategies doesn't mean I failed, but that I have reached a point where new motivation and structure are needed.

I still worry if I'm publishing enough. However, the difference between now and when I joined the writing group is that I have five years of learning through failures and successes that remind me I can engage in research and that my end goal isn't perfection. Most importantly, when I meet with my writing group, I am reminded that faculty librarianship is not simply about the number of publications we have, but about the relationships we build along the way, and the friends, patrons, and colleagues we support.

\section{Accountability and moral support - Anne}

In fall 2008, I started a faculty position at a Research I university with stringent publishing and grant-writing requirements. Much of my previous research was collaborative and proprietary, which meant I had to start out on my own and build a completely new research agenda in addition to teaching responsibilities and all new course preps. Being part of this writing group helped combat the lonely academic existence and provided encouragement and accountability that alleviated these challenging years.

- Sharing work strategies. Fellow group members often struggle with similar issues, regardless of discipline, and as a result have often already figured out good solutions.
During our meetings, members share what worked for them, which allows others to implement the same without testing and trying out various other ways. Some of these strategies, like the Pomodoro Technique, are listed below.

- Progress tracking and accountability. Rather than having your own private spreadsheet and to-do list, our writing group has a shared list, where writing goal progress is tracked every other week. This often provides that extra nudge to get things done.

- Support through difficult times. It is very easy to get disheartened after paper rejections. A supportive writing group can help keep things in perspective and can get one motivated to tackle revisions and resubmissions.

A new job and a move to a different city required me to say farewell to my former writing group. I am an academic librarian now, and my publishing demands are considerably more manageable. That said, librarians have a wide array of responsibilities, and working in an understaffed library means I wear many hats, so there is very little time available to devote to research and scholarship. Perhaps it is time to start my own local writing group.

\section{Sharing struggles and successes-Karin}

I was one of the founding members of the group in January 2009 and a new assistant professor on the tenure track. This writing group provided me critical support so that I could be a productive faculty member.

- Sharing struggles. I found my new position isolating and overwhelming. I felt ill-equipped to publish sufficiently to meet targets for tenure. I also had my daughter at the start of my third year, and the sleep deprivation and constant pull between work and home was trying. This group inherently understood the depths of my stress, allowed me to vent about my struggles, and the collective knowledge of others helped me address my challenges so I could actually get work done. 
- Set concrete, manageable goals. I was constantly over-ambitious in my writing goals and also allowed other things to get in the way of writing. Having to articulate and revise my goals for this group forced me to be more realistic about what I could get done, and also provided a system of accountability so that I could prioritize writing.

- Celebrate successes. As academics, we are very good at criticizing ourselves and others. But we are our most productive when we feel accomplished and empowered. When we met our goals or had a publishing or grant proposal success, we toasted each other. Celebrating these victories with wonderful friends is a way to find joy in my job and see how incremental progress can lead to longer term achievements.

I am now tenured, and the sources of my stress have changed dramatically since those early days-I no longer fear losing my job, but the demands on my time and research expectations are still daunting. I am grateful for this writing group that supports me as I navigate this midcareer stage.

\section{Suggested resources and final ideas}

A writing group is a critical and important step towards meeting your important writing goals. However, how you manage your actual writing time is a second vital ingredient. Here are a few resources that we've found useful for making progress on our writing.

1. How to Write a Lot by Paul J. Silvia is a foundational document for our group, and this short book packs a lot of practical punch as it guides its readers into becoming productive academic writers through discipline and good use of time. ${ }^{2}$ The first part of the book delves into writing and how a group can help create routine writing habits. The second part of the book goes into writing style and the formulas for writing journal articles or books.

2. One of the core books for our group, already mentioned in the introduction, is
Every Other Thursday, which describes how seven professional women scientists gathered together for "practical and emotional support." This is not a how-to book, but rather a rich description of the group, its members, the challenges they faced, and the advice and support the group provided as these women progressed through their careers. As the author writes in the preface: "This book is about the power of not trying to go it alone." Part three specifically talks about how to start your own group and how to keep it going.

3. To set yourself up for a productive writing session, you need to remove all obstacles and make writing a hard-wired habit. The Sweet Spot by Christine Carter describes the science of habit formation and guides you through establishing your own habits. ${ }^{3}$ Suggestions related to a writing habit might include organizing your writing space at the end of each writing session or leaving yourself a list of next steps, so you start your next session with clear goals in mind.

4. Establishing effective writing goals is a skill that takes practice. On his blog, "Time Zillionaire," Matt Sandrini shares ideas on how to establish longer-term goals, and then how to break them down into feasible weekly and daily tasks. ${ }^{4}$

5. Developing your ability to concentrate and do "deep work" makes writing sessions more productive. A great reference with strategies for how to develop your "mental muscle," and avoid the call of your smartphone, is Cal Newport's book Deep Work and his blog "Study Hacks.", 6

6. Setting up for deep work means dealing with our addictions to email and social media. Programs like Freedom can block access to chosen websites or applications during regularly scheduled times. ${ }^{7}$

7. Help, I just can't get started! The Pomodoro Technique is the perfect tool to jump over that first hurdle to get the writing going each day. ${ }^{8}$ Remove all distractions and set a timer for 25 minutes. When that timer goes off, congratulate yourself, take a fiveminute break, and start again. 


\section{Conclusion}

Being part of a writing group makes the journey to publishing, and eventually tenure, a more social and pleasant process. Sound advice and encouragement with a bit of accountability mixed in has been a great recipe for us, and we encourage you to start your own group and realize those publishing dreams.

\section{Acknowledgements}

A heartfelt thanks to all our current and former writing group members for their advice, support, and continued friendship.

\section{Notes}

1. Ellen Daniell, Every other Thursday: Stories and strategies from successful women scientists (New Haven, Connecticut: Yale University Press, 2008).
2. Paul J.Silvia, How to Write A Lot: A Practical Guide to Productive Academic Writing (Washington, D.C.: American Psychological Association, 2014).

3. Christine Carter, The Sweet Spot: How to Find Your Groove at Home and Work (New York: Ballantine Books, 2015).

4. Matt Sandrini, "Time Zillionaire," www. timezillionaire.com.

5. Cal Newport, Deep Work: Rules for Focused Success in a Distracted World (New York: Grand Central Publishing, 2016).

6. Cal Newport, "Study Hacks," calnewport. $\mathrm{com} / \mathrm{blog} /$.

7. "Freedom," https://freedom.to/.

8. "Do More and Have Fun with Time Management," Cirillo Company, October 18 2017, https://cirillocompany.de/pages /pomodoro-technique. $\approx$

("OpenCon 2018," continues from page 136)

work with the Open and Collaborative Science in Development Network, whereby multiple projects in Latin America, Africa, the Middle East, and Asia are using open science as a strategy for risk and harm reduction and as a process to address our noninnocence and responsibility. She outlined how the community/researcher relationship is never neutral, especially when privilege and conflicting agendas create complex working environments.

The panel ended with Leslie Chan, associate professor in the Centre for Critical Development Studies at the University of Toronto, who fascinated us with a discussion on how technology and algorithms are not neutral, but that they are written for a specific form of success and can be harmful. Chan also spoke of "Plan S," an initiative for open access science publishing, and its problematic dependence on article processing charges, which in turn can create new inequalities in publishing by empowering the already powerful.
Thank you, ACRL, for this unique opportunity. We look forward to serving on ReSEC and continuing to put the conversation of OpenCon into action.

\section{Notes}

1. M. Altman and C. Bourg, "A Grand Challenges-Based Research Agenda for Scholarly Communication and Information Science," MIT Grand Challenge PubPub Participation Platform (2018), https://doi. org/10.21428/62b3421f.

2. https://doathon.opencon2018.org /participate\#projects.

3. https://github.com/sparcopen /doathon/issues/87.

4. OpenCon2018, "Diversity Equity and Inclusion in Open Research and Education," https://opencon2018.sched.com/event /H9h6/diversity-equity-and-inclusion-in -open-research-and-education.

5. http://www.blanknoise.org/.

6. http://www.blanknoise.org/museum -of-street-weapons-of-defense/. z 